\title{
Methylene Blue Reduces Peritoneal Adhesions in Syrian Golden Hamsters That Undergo Hepatopancreatic Surgical Procedures
}

\author{
Cíntia Yoko MORIOKA ${ }^{1-5,7}$, Marcel Cerqueira Cesar MACHADO ${ }^{1}$, Jose Pinhata OTOCH ${ }^{2,4}$, Seiji \\ SAITO $^{5}$, Joelmir Lucena Veiga da SILVA ${ }^{6}$, Akiharu WATANABE ${ }^{5}$, Hideki ARAI ${ }^{7}$, Takashi \\ SAKAMOTO $^{7}$, Keiichi YAMAMOTO ${ }^{7}$, Luis Francisco Poli de FIGUEIREDO ${ }^{2}$ \\ ${ }^{1}$ Emergency Medicine Department, University of São Paulo, São Paulo, Brazil \\ ${ }^{2}$ Experimental Surgery Research Laboratory (LIM26),Depart. of Surgery, University of São Paulo, São \\ Paulo, Brazil \\ ${ }^{3}$ Advantage Health. São Paulo,Brazil \\ ${ }^{4}$ Sírio Libanês Hospital, São Paulo,Brazil \\ ${ }^{5}$ Third Department of Internal Medicine, University of Toyama, Toyama, Japan \\ ${ }^{6}$ Practice Functional Laboratory, School Medical of Olinda,Olinda,,Brazil \\ ${ }^{7}$ Second Department of Surgery, Toyama, Japan
}

\begin{abstract}
Background: Tissue ischemia, mechanical or thermal trauma, infection and foreign body reaction predispose to adhesion formation. Adhesion formation resembles an inflammatory process. Sometimes, they appear as a bridge to wound healing, however,in other times it may cause small bowel obstruction. Methylene blue (MB)is known to inhibit the generation of oxygen radicals. Therefore, it may be used as an antioxidant reducing adhesion formation. Objective. To analyse the effectiveness of using methylene blue in hamsters that undergo hepatectomy or pancreatectomy. Methods. Syrian golden hamsters were divided into 6 groups:1.Partial pancreatectomy with splenectomy (PPS),2.PPS and MB (PPS-MB),3.Partial hepatectomy (PH),4.PH and MB (PH-MB),5.Sham operation (SO), and 6.Sham operation and MB (SOMB).MB was administered intraperitoneally before closing abdominal wall. Side effects were observed. Animals were sacrificed 10 days later and adhesions were quantified. Results. Adhesions were present in all animals (100\%)of PH group and 3 of $5(60 \%)$ of PPS group. In PH-MB and SO groups, 1 of 5 hamsters $(20 \%)$ in each group showed adhesions. No adhesions were found in PPS-MB and SO-MB treated groups. None of animals showed loss of weight. Conclusion. This study demonstrated that methylene blue administration showed to be effective to prevent adhesion formation in hepatopancreatic surgical procedures.
\end{abstract}

Keywords: Animal; Adhesion; Methylene Blue; Pancreatectomy; Hepatectomy; Splenectomy; Peritoneum.

\section{Introduction}

Tissue ischemia, mechanical or thermal trauma, infection and foreign body reaction predispose to adhesion formation (diZerega \& Campeau, 2001; Liakakos et al., 2001). Adhesion formation resembles an inflammatory process. Development of intraperitoneal adhesions is a dynamic process whereby surgically traumatized tissues in apposition bind through fibrin bridges which become organized by wound repair cells, often supporting a rich vascular supply as well as neuronal elements (Treutner \& Schumpelick, 2000; Senthilkumar \& Dreyer, 2006). Sometimes, they appear as a bridge to wound healing, however, in other times it may cause small bowel obstruction, leading to exploratory laparotomy. Methylene blue (MB) is known to inhibit the production of oxygen radicals. Therefore, it may be used as an antioxidant agent to reduce adhesion formation. Syrian golden hamsters are animals used for evaluation of hepatopancreatic surgical procedures. In the present study, our aim was to elucidate the effectiveness of using methylene blue in hamsters that undergo hepatectomy or pancreatectomy. 


\section{Materials and Methods}

\section{Animals}

Thirty Syrian golden hamsters (APG strain) of both sexes, aging from 8 to 26 weeks, weighing in average $134 \mathrm{~g}$ were used. They were maintained in the Laboratory Animal Center of University of Toyama, in a $12 \mathrm{~h} / 12 \mathrm{~h}$ light/dark cycle, fed standard rations and water ad libitum.

\section{Experimental Protocol}

Animals were divided in 6 groups: 1. Partial pancreatectomy with splenectomy (PPS), 2. PPS and MB (PPS$\mathrm{MB})$, 3. Partial hepatectomy (PH), 4. PH and MB (PH-MB), 5. Sham operation (SO), and 6. Sham operation and MB (SO-MB). MB was administered intraperitoneally before closing abdominal wall. Side effects were observed. Animals were sacrificed 10 days later and adhesions were quantified.

\section{Substance}

Methylene blue was purchased from Sigma Co., Japan. It was diluted with saline solution $0.9 \%$ until $0.2 \%$ $(20 \mathrm{mg} / \mathrm{kg})$.

\section{Surgical procedures 4.1.Anesthesia}

All hamsters were anesthetized with diethyl-ether inhalation and pentobarbital $(5 \mathrm{mg} / \mathrm{kg} / \mathrm{body}$-weight $)$ intraperitoneally).

\subsection{Partial pancreatectomy and splenectomy}

Animals were placed in a sterile surgical field. Asepsy and antisepsy were done. Left subcostal incision was made. After ligation of fat string, pancreatectomy of splenic lobe and splenectomy were performed (Morioka et al., 2000). Abdominal wall was closed in two layers with nylon 4.0 sutures.

\subsection{Partial hepatectomy}

Right subcostal incision was made. After cutting ligaments, frontal lobe of the liver was ligated with silk 3.0 sutures. Abdominal wall was closed, as described.

\subsection{Sham operation}

Right subcostal incision was made in 5 animals and left subcostal incision in 5 animals. Liver and pancreas were manipulated, exposing spleen and pancreas out of abdominal cavity. Abdominal wall was closed.

\section{Methylene blue administration}

Before closing abdominal wall, MB was injected intraperitoneally in a volume corresponding to $10 \%$ of body weight transformed in $\mathrm{ml}$.

\section{Statistics}

The hierarchical log-linear model was used for the multivariate analysis of the data; this analysis took into account the three factors of the applied experimental design (adhesion formation, type of surgery, and MB administration). The effect of administration of MB within each type of surgery was made by the Fisher's exact test. Two-tailed P values less than 0.05 were considered significant. The SPSS 13.0 for Windows was used to analyze data.

\section{Ethics}

These experiments were approved by the Ethics Committee of University of Toyama, Toyama, Japan.

\section{Results}

Adhesions were present in all animals (100\%) of PH group and 3 of 5 (60\%) of PPS group. In PH-MB and SO groups, 1 of 5 hamsters (20\%) in each group showed adhesions. No adhesions were found in PPS-MB and SO-MB treated groups. Table 1 shows the frequency of adhesion formation in the six groups of hamsters. Bivariate analysis showed that adhesion formation was significantly related to the type of surgery $(\mathrm{P}=0.006)$, as well as adhesion formation was significantly reduced by the $\mathrm{MB}$ administration $(\mathrm{P}<0.001)$. In 
particular, administration of MB significantly reduced adhesion in partial hepatectomy (20\% with MB vs. $100 \%$ without $\mathrm{MB} ; \mathrm{P}=0.048$ ) while the difference did not reach the statistical significance in partial pancreatectomy with splenectomy (no adhesion with MB vs. 60\% without MB). Considering the sham operation, one hamster presented adhesion formation in $\mathrm{SO}$ vs. no adhesion in $\mathrm{SO}-\mathrm{MB}(\mathrm{P}=1.000)$.

Table 1. Presence of peritoneal adhesions

\begin{tabular}{|l|c|c|l|l|}
\hline & $\begin{array}{c}\text { Implanted } \\
\text { animals }\end{array}$ & With adhesions & $\mathrm{F}(\%)$ & $p$ \\
\hline PPS & 5 & 3 & $60^{a}$ & ${ }^{a}<0.05$ \\
\hline PPS-MB & 5 & 0 & $0^{b}$ & \\
\hline PH & 5 & 5 & $100^{a, c}$ & ${ }^{b}<0.001$ \\
\hline PH-MB & 5 & 1 & $20^{b, c}-{ }^{c}<0.05$ \\
\hline SO & 5 & 1 & 20 & \\
\hline SO-MB & 5 & 0 & 0 & \\
\hline
\end{tabular}

PPS: partial pancreatectomy with splenectomy, PPS-MB: PPS and methylene blue, PH: partial hepatectomy, PH-MB: PH and methylene blue, SO: Sham operation, SO-MB: SO and methylene blue

\section{Discussion}

The events that precede adhesion formation are common to both adhesion development and wound healing. Adhesion formation is a result of a disruption in the normal physiological process of peritoneal healing and resembles an inflammatory process in many ways. Mediators of inflammation, such as free radicals, may be also involved in this process. The main effect of $\mathrm{MB}$ is inhibition of guanylate cyclase, the target site of nitrite oxide (NO). MB is known to show pharmacological actions, such as, the generation of oxygen radicals, direct inhibition of nitric oxide synthetase (NOS), inhibition of potassium channels, and other nonspecific actions. NO ameliorates tissue injury during endotoxemia and sepsis in vivo.

Galili et al.(1998) reported that MB was very effective in the prevention of adhesion formation. Kluger et al. (2000) studied the effects of decreasing concentrations of MB solution administered i.p. to reduce postoperative adhesions in a rat uterine horn model and concluded that the best effective concentration of MB was 1\%. Mahdy et al. (2008) also reported that in rats treated with MB $1 \%$ and studied after two weeks showed lower adhesions. In the present study, $0.2 \%$ was effective. Thus, it might be appropriate to use a solution of MB during abdominal surgery before closure of abdominal wall.

Orita et al. (1992) reported that peritoneal macrophages play a crucial role in adhesion formation by secreting compounds that cause proliferation of fibroblasts. This response includes polymorphonuclear leukocytes and surface exsudate. The second phase of the healing process is observed as a response similar to the delayed inflammatory reaction, and fibroblasts, collagen, plasma cells and macrophages are usually observed, with formation of foreign body granulomas (diZerega, 1997). Moreover, it has been reported that MB may inhibit peritoneal lymphocyte and macrophage function in vitro (Galili et al. 1998).

Heydrick et al. (2007) stated that MB induced a $>50 \%$ regression in peritoneal adhesions after 7 days as an antioxidant and increased fibrinolytic activity in peritoneal fluid at 24 hours in rats. However, it did not decrease the peritoneal adhesions at $24 \mathrm{~h}$. On the other hand, Panahi et al. (2012) showed that saline showed to be better when compared with $\mathrm{MB}$ in a rat cecum model, different from our model that was in a hepatopancreatic procedure.

\section{Conclusion}

Methylene blue administration demonstrated to be effective to prevent adhesion formation in hepatopancreatic surgical procedures. It can avoid unnecessary surgeries due to adhesions. However, further studies will be necessary.

\section{Acknowledgments}

We would like to thank the Laboratory Animal Center and the Molecular Research Genetics Center, University of Toyama, Japan, Dr. Keiichiro Kita, Dr. Kouji Ohzawa, Dr. Yuji Nakada, Dr Shigeru Takemori, Mr Eduardo Kenichi Morioka, and Mr Yukio Morioka for their helpful comments. 


\section{Disclosure Statement}

The authors declare that there is no conflict of interest.

\section{References}

[1] diZerega GS. (1997) Biochemical events in peritoneal tissue repair. Int J Pancreatol (577):10-16.

[2] diZerega GS, Campeau JD. (2001) Peritoneal repair and post-surgical adhesion formation. Hum Reprod Update 7 (6):547-555. https://doi.org/10.1093/humupd/7.6.547

[3] Galili Y, Ben-Ayraham R, Rabau M, Klausner J, Kluger Y. (1998) Reduction of surgery-induced peritoneal adhesions by methylene blue. Int J Pancreatol 175 (1): 30-32. https://doi.org/10.1016/s0002-9610(97)00232-8

[4] Heydrick SJ, Reed KL, Cohen PA, Aarons CB, Gower AC, Becker JM, Stucchi AF. (2007) Intraperitoneal administration of methylene blue attenuates oxidative stress, increases peritoneal fibrinolysis and inhibits intraabdominal adhesion formation. J Surg Res 143(2):311-9. https://doi.org/10.1016/j.jss.2006.11.012

[5] Kluger Y, Weinbroum A, Ben Ayraham R, Galili Y, Klausner J, Rabau M. (2000) Reduction in formation of peritoneal adhesions by methylene blue in rats: a dose response study. Eur J Surg 166 (7):568-571. https://doi.org/10.1080/110241500750008655

[6] Liakakos T, Thomakos N, Fine PM, Dervnis C, Young RL. (2001) Peritoneal adhesions: etiology, pathophysiology, and clinical significance. Recent advances in prevention and management. Dig Surg 18 (4): 260-273. https://doi.org/10.1159/000050149

[7] Mahdy T, Mohamed G, Elhawary A. (2008) Effect of methylene blue on intra-abdominal adhesion formation in rats. Int J Surg 6(6):452-5. https://doi.org/10.1016/j.ijsu.2008.08.004

[8] Morioka CY, Saito S, Kita K, Watanabe,A. (2000) Curative resection of orthotopically implanted pancreatic cancer in Syrian golden hamsters. Int J Pancreatol 28 (3): 207-213. https://doi.org/10.1385/ijgc:28:3:207

[9] Orita H, Fukasawa M, Girgis W, diZerega GS. (1992) Inhibition of postsurgical adhesions in a standardized rabbit model: intraperitoneal treatment with tissue plasminogen activator. Int $\mathbf{J}$ Pancreatol. 136 (3): 172-177.

[10] Panahi F, Sadraie SH, Khoshmohabat H, Shahram E, Kaka G, Hosseinalipour M. (2012) Macroscopic and pathological assessment of methylene blue and normal saline on postoperative adhesion formation in a rat cecum model. Int $J$ Surg 10(9):537-4. https://doi.org/10.1016/j.ijsu.2012.08.009

[11] Senthilkumar MP, Dreyer JS. (2006) Peritoneal adhesions: pathogenesis, assessment and effects. Trop Gastroenterol 27 (1):11-18.

[12] Treutner KH, Schumpelick V. (2000) $\square$ Prevention of adhesions. Wish and reality $\square$. Chirurg 71 (5): 510-7. https://doi.org/10.1007/s00104005084 